\title{
Drying Kinetics, Physicochemical Properties and Sensory Quality of the Instant Foxtail Millet as Affected by Drying Methods
}

\author{
Yingqiang Wang*๑ ${ }^{\oplus}$, Hongxia Zhao ${ }^{\circledR}$, Xi Song, Wenjie Zhang, Feng Yang \\ College of Agriculture and Forestry, Longdong University, 745000, Qingyang, China
}

Key words: instant foxtail millet, drying kinetics, physicochemical properties, sensory quality

The instant foxtail millet was prepared using microwave vacuum drying (MVD), microwave-hot air drying (MHAD), hot air drying (HAD) and traditional roasting (TR). Their effects on drying kinetics, physicochemical properties as well as sensory quality were evaluated and compared. Results showed that the total drying time varied with the drying method used and was about 160, 100, 260, and 45 min for MVD, MHAD, HAD and TR, respectively. The effective moisture diffusion coefficients $\left(D_{\text {eff }}\right)$ were $6.57 \times 10^{-9} \mathrm{~m}^{2} / \mathrm{s}, 9.80 \times 10^{-9} \mathrm{~m}^{2} / \mathrm{s}, 4.14 \times 10^{-9} \mathrm{~m}^{2} / \mathrm{s}$ and $6.20 \times 10^{-9} \mathrm{~m}^{2} / \mathrm{s}$ for MVD, MHAD, HAD and TR, respectively. Drying resulted in a significant decrease in $L^{*}$ and an increase in $a^{*}$ and $b^{*}$ of the color of products. MVD, MHAD and HAD products had a comparable rehydration ratio and cooking time. Scanning electron microscopy and rehydration process revealed that MHAD and MVD samples had a similar structure with the HAD sample. Drying caused a loss of $6.5-54.9 \%$ in the total phenolic content and a loss of 38.4-62.2\% in total yellow pigment content. MVD millet displayed the highest total phenolic content (142.56 mg GAE/100 g dry matter) and yellow pigment content ( $9.56 \mathrm{mg} \mathrm{CE} / \mathrm{kg}$ dry matter). In sensory evaluation, MHAD, HAD and MVD samples had comparable scores and were all accepted by the panelists, either in dry or rehydrated form. MHAD and MVD can be used as an alternative to hot air drying or traditional roasting in the production of the instant millet due to shorter drying time and better product quality.

\section{INTRODUCTION}

Foxtail millet (Setaria italica L.) belongs to the small-seeded subsistence cereal crop in the family Poaceae [Pradeep \& Sreerama, 2015]. It has excellent drought resistance and is extensively cultivated in the arid and semi-arid areas of the world [Sharma \& Niranjan, 2018]. Foxtail millet grains are rich in a variety of essential nutritive compounds, which are comparable to that of major cereals such as wheat and rice [Saleh et al., 2013]. It is reported that the protein content in millet grains is equal or even superior to that in wheat, rice, maize and sorghum grains [FAO, 2005]. Foxtail millets also contain phytochemicals and micronutrients such as phenolic compounds and carotenoids. The total yellow pigment content in millet grains was found to be $17.32-3.46 \mathrm{mg} / \mathrm{kg}$ and higher than that in maize, wheat and sorghum [ $\mathrm{Li}$ et al., 2021]. Total phenolic and total flavonoid content was $72.70 \mathrm{mg} / 100 \mathrm{~g}$ and $87.63 \mathrm{mg} / 100 \mathrm{~g}$, respectively [Pradeep \& Sreerama, 2015; Zhang et al., 2017]. It became a staple food source for humans before the rise of wheat and rice foxtail millet and played an increasingly important role in enhancing nutritional and food security [Wang et al., 2017]. Sharma \& Niranjan [2018] and Saleh et al. [2013] gave an insight into the nutritional quality, health benefits and processing utilization in their review articles publicized in recent several years. They highlighted that the foxtail millet remained an under-utilized state as an excellent food source.

The traditional methods used for cooking the foxtail millet in China include roasting and boiling [Bi et al., 2019]. Boiling is the primary method of cooking and the boiled foxtail millet porridge was widely eaten in daily diet by Chinese or in traditional meals as a nourishing gruel or soup for pregnant and nursing women for food therapy [Sharma \& Niranjan, 2018]. Besides these, the foxtail millet was also processed into a handful of foods such as yellow wine prepared by fermentation, popping meals, instant millet powder prepared by roasting or extrusion expansion and so on. However, there are some obvious problems such as fewer processing categories, low processing rate as well as missing of instant processing products conforming to traditional consumption habits, which are restricting its consumption in China. Processing them using traditional as well as contemporary methods for preparation of value-added and convenience products would certainly diversify their food uses [Pradeep \& Sreerama, 2015]. Instant rice or quick cooking rice is defined as the processed dried whole grain, which belongs to granular $\alpha$-rice products prepared by gelatinization and dehydration and could be ready for eating after rehydrating for a few

\footnotetext{
* Corresponding Author:

E-mail: sxxds2008@163.com (Y. Wang)
} 
minutes in hot water [Sripinyowanich \& Noomhorm, 2013; Wang et al., 2017]. Such a kind of product provides a convenient way to consume rice for modern people and is increasing in popularity [Hsu et al., 2015]. To obtain the instant rice, the freshly cooked rice must be dehydrated to a certain moisture content, practically 6-12 g/100 g dry matter, so the drying operation is one of the critical steps in the preparation of instant rice [Luangmalawat et al., 2008]. There are many drying techniques to dehydrate foods including the instant rice. Hot-air drying is the most widely used drying method due to its little capital, simple equipment and low energy input, but it also generates the dried food product with a low quality due to long time and high process temperature [Luangmalawat et al., 2008; Rewthong et al., 2011; Ritudomphol \& Luangsakul, 2019; Shingare \& Thorat, 2013; Sripinyowanich \& Noomhorm, 2013]. Freeze drying under vacuum conditions is the best water removal method for all kinds of foods, while it requires long drying time that would lead to high energy consumption and high capital investment. Therefore, freeze drying is applied only with the high added-value products [Lenaerts et al., 2018; Lin et al., 1998].

Microwave-assisted drying is a more rapid method of moisture removal based on microwave heating substitution for convective or conduction heat transfer [Zhang et al., 2006]. The advantages of microwave-assisted drying include shorter drying time, reduced energy consumption, improved product quality and flexibility in producing a wide variety of dried products [Lin et al., 1998; Zhang et al., 2006]. The application of microwave energy with hot air drying of the cooked rice could reduce the drying time by $25 \%-50 \%$ as compared to the conventional drying [Jiao et al., 2014; Palamanit et al., 2020]. Sripinyowanich \& Noomhorm [2013] dried the cooked rice using the microwave vibro-fluidized bed and the vibro-fluidized bed and found that the microwave vibro-fluidized bed drying had the highest drying rate and the shortest drying time as well as the lowest energy. The research of Lenaerts et al. [2018] showed that the microwave drying with or without vacuum can be a proper alternative to freeze drying for mealworms because microwave dried mealworms had no differences with the freeze dried ones in the proximate composition and displayed a lower oxidation status of the fat. The microwave-assisted convective dried instant rice had lower true densities and faster rehydration rate than air-dried samples due to a porous structure of the microwave-dried samples [Jiao et al., 2014; Le \& Jittanit, 2015, 2012]. Although the use of microwave energy in food drying has a huge advantage in shortening drying time and improving energy efficiency, too rapid moisture transport under microwave heating conditions can cause quality damage or undesirable changes in the food texture due to "puffing" in some cases. However, this might or might not be a limitation, depending on the desired quality attributes of the final product [Zhang et al., 2006]. Microwave-related drying has been applied widely to dehydrate fruits and vegetables and is not common in grains and cereals drying [Wang et al., 2017].

Up to date, most research on instant grains is mainly focused on hot air drying of the instant rice and the effect of pretreatment prior to drying on quality. Limited studies are available concerning the effects of different drying methods on quality of the instant millet, like foxtail millet. Therefore, the objective of this study was to compare the effects of four drying methods (microwave vacuum drying (MVD), microwave-hot air drying (MHAD), hot air drying (HAD) and traditional roasting (TR)) on the physicochemical properties, and sensory quality of the instant foxtail millet to provide more information for its value-added processing.

\section{MATERIALS AND METHODS}

\section{Materials}

Freshly hulled raw foxtail millet was purchased from a local supermarket (Qingyang, Gansu, China) and stored in a cool and dry place after arrival to lab for further use. All chemical reagents used were of analytical grade.

\section{Cooking of the millet}

The cleaned raw millet was soaked in plenty of tap water for $3 \mathrm{~h}$ at room temperature. After soaking, the steeping water was drained off from the millet and the obtained millet was added into the tap water at a $3: 1(w / v)$ ratio of millet to water and steamed at high pressure $\left(121^{\circ} \mathrm{C}, 0.12 \mathrm{MPa}\right)$ for $40 \mathrm{~min}$. After cooking, the gelatinized millet granules were spread out on the plate and cooled to room temperature. The resulting cooked millet was used for MVD, MHAD and HAD. The cleaned raw millet was directly applied to TR.

\section{Drying of the cooked millet and raw millet roasting}

Microwave-vacuum drying (MVD): a batch of $300 \mathrm{~g}$ cooked millet was dried in a lab-scale microwave-vacuum dryer (ORW1.2S-5Z, Orient Microwave Co., Ltd., Nanjing, China). The samples to be dried were arranged in a single layer of $5 \mathrm{~mm}$ on a tray and the microwave-vacuum dryer was operated at $5 \mathrm{kPa}$ (absolute pressure) and the power intensity for each drying test was $2.5 \mathrm{~W} / \mathrm{g}$ (original mass of $300 \mathrm{~g}$ the cooked sample). The temperature of the material to be dried was monitored through an infrared temperature sensor and controlled at $60^{\circ} \mathrm{C}$ using an automatic on-off controller to avoid local charring.

Microwave hot air drying (MHAD): a batch of $300 \mathrm{~g}$ cooked millet was dried in a lab-scale microwave convection dryer (ORW 1.0S-3000R, Orient Microwave Co., Ltd.,). The samples to be dried were arranged in a single layer of $5 \mathrm{~mm}$ on a tray. The power intensity of $1.25 \mathrm{~W} / \mathrm{g}$ was used. The temperature of the material to be dried was monitored through an infrared temperature sensor and controlled at $60^{\circ} \mathrm{C}$. Hot air with a temperature of $60^{\circ} \mathrm{C}$ was fed into the dryer chamber and crossed the material surface at $0.5 \mathrm{~m} / \mathrm{s}$ velocity.

Hot air drying (HAD): a batch of $300 \mathrm{~g}$ cooked millet was dried in an electricity heat drum wind drying oven (DHG-9420A, Yiheng Instrument Co., Ltd., Shanghai, China). The samples to be dried were arranged in a single layer of $5 \mathrm{~mm}$ on a tray. During the period of drying, hot air with a temperature of $60^{\circ} \mathrm{C}$ circulated in the box at $0.5 \mathrm{~m} / \mathrm{s}$ velocity.

Traditional roasting (TR): about $300 \mathrm{~g}$ of raw foxtail millet grains were spread on a tray as a single layer of thickness of $5 \mathrm{~mm}$ and dried and roasted at the selected temperature of $150^{\circ} \mathrm{C}$. The electricity heat drum wind drying oven mentioned above was applied. 
During the drying and roasting process, moisture loss of the samples was recorded at a regular interval using a digital balance (JH2102, Shanghai Precision \& Scientific Instrument Co., Ltd., Shanghai, China) with $0.01 \mathrm{~g}$ precision. The samples were dehydrated until a moisture content of less than $7 \mathrm{~g} / 100 \mathrm{~g}$ was reached. Each drying experiment was conducted in triplicate. After the drying process was completed, the dried products were cooled down to room temperature and then kept in sealed polyethylene bags in desiccators with a silica gel-self indicator.

\section{Drying characterization evaluation}

\section{Calculation of moisture ratio and drying rate}

During drying process, drying rate was determined as follows:

$$
\text { Drying rate }=\frac{X_{t}-X_{t+\Delta t}}{\Delta t}
$$

where: $X_{\mathrm{t}}, X_{\mathrm{t}+\Delta \mathrm{t}}$ is moisture content (kg water $/ \mathrm{kg}$ dry matter) at time $t$ and $t+\Delta t$, respectively, $\Delta t$ is time interval (min).

The change of moisture content in time was defined as a dimensionless parameter and expressed as the following equation:

$$
M R=\frac{X-X_{e}}{X_{0}-X_{e}}
$$

where: $M R$ is the dimensionless moisture ratio, $X, X_{0}$ and $X_{\mathrm{e}}$ stand for the initial moisture content, the moisture content at drying time $t$ and the equilibrium moisture content, respectively. All results were expressed per dry basis (kg water/kg dry matter). The Eq. 2 can be simplified to:

$$
M R=\frac{X}{X_{0}}
$$

because the value of dynamic equilibrium moisture content $X_{\mathrm{e}}$ was very small as in comparison with $X_{0}$ and $X$ [Kaya et al., 2007].

\section{Calculation of moisture diffusivity}

Drying process was proven to occur mostly in the falling rate period, and moisture transfer during drying was controlled by internal diffusion. Fick's second diffusion law (Eq. 4) had been widely used to describe the drying process in the falling rate period for most biological materials [Schoessler et al., 2012].

$$
\frac{\partial X}{\partial t}=\Delta\left[D_{e f f}(\nabla X)\right]
$$

where: $D_{\text {eff }}$ is the effective moisture diffusion coefficient $\left(\mathrm{m}^{2} / \mathrm{s}\right)$, which was a mass diffusion property of the product.

Assuming unidirectional and constant moisture diffusion, negligible shrinkage and temperature change during drying, analytical solutions of Eq. 4 for an infinite slab geometry are expressed as Eq. 5:

$$
\frac{X-X_{e}}{X_{0}-X_{e}}=\frac{8}{\pi^{2}} \sum_{n=0}^{\infty} \frac{1}{(2 n+1)^{2}} \times \exp \left(-\frac{(2 n+1)^{2} \pi^{2} \times D_{\text {eff }}}{4 L^{2}} \times t\right)
$$

where: $L$ is the thickness of the sample slices (m).
For long drying periods, the first term of the series solution in Eq. 5 can be used as stated in Eq. 6.

$$
M R=\frac{8}{\pi^{2}} \exp \left(-\frac{\pi^{2} \times D_{e f f}}{4 L^{2}} \times t\right)
$$

Eq. 6 can be simplified to a straight-line equation as follows:

$$
\ln M R=\ln \left(\frac{8}{\pi^{2}}\right)-\frac{\pi^{2} \times D_{\text {eff }}}{4 L^{2}} \times t
$$

Plotting experimental drying data in terms of $\ln M R$ versus time, a straight line can be obtained. $D_{\text {eff }}$ was calculated according to the slop of the straight line.

\section{Analysis of physicochemical and sensory properties}

\section{Moisture content}

The moisture content of the raw and cooked samples was determined by the oven method at $105^{\circ} \mathrm{C}$ [AOAC, 1997] and expressed per dry basis. Every experiment was repeated three times.

\section{Color parameters}

A chromaticity instrument (CR-400, Konica Minolta Co., Tokyo, Japan) calibrated using a white standard board was used to measure the color of the millet sample surface. Readings were expressed in CIE1976 $L^{*} a^{*} b^{*}$ scale, where $L^{*}$ measures lightness, with 100 being very white and 0 being dark; the $a^{*}$ value measures green $(-)$ to red $(+)$ and $b^{*}$ represents blueness $(-)$ to yellowness $(+)$. Each sample was tested in five different locations. Total color difference $(\Delta E)$, hue angle $\left(h^{\circ}\right)$ and chroma $\left(C^{*}\right)$ were also calculated according to the following equations [Chong et al., 2008]:

$$
\begin{aligned}
& \Delta E=\sqrt{\left(\Delta L^{*}\right)^{2}+\left(\Delta a^{*}\right)^{2}+\left(\Delta b^{*}\right)^{2}} \\
& h^{\circ}=\operatorname{arctg}\left(b^{*} / a^{*}\right) \\
& C^{*}=\sqrt{\left(a^{*}\right)^{2}+\left(b^{*}\right)^{2}}
\end{aligned}
$$

where: $\Delta L^{*}, \Delta a^{*}, \Delta b^{*}$ are the difference value of $L^{*}, a^{*}$ and $b^{*}$ between the raw millet and the dried ones, respectively. The hue angle $\left(h^{\circ}\right)$ expresses the color nuance; the values are defined as follows: red-purple: $0^{\circ}$, yellow: $90^{\circ}$, bluish-green: $180^{\circ}$, blue: $270^{\circ}$. The $C^{*}$ expresses chromaticity and denotes the purity or the saturation of the color.

\section{Rehydration ratio and cooking time}

Rehydration ratio of the dried instant millets was measured according to the method described by Wang L. et al. [2013]. In brief, $5 \mathrm{~g}$ of the dried sample was immersed in $100 \mathrm{~mL}$ of distilled water at room temperature. Samples were drained and weighed at an interval of $30 \mathrm{~min}$ for $300 \mathrm{~min}$. After taking out of the water, the excess water was removed using a dry blotting paper, and then the weight was measured. Rehydration ratio was calculated according to the mass ratio of the rehydrated and original dried sample at a point. Every experiment was conducted in triplicate and the results were expressed as the mean values. 
Cooking time was defined as the time which the millet grains required to be fully rehydrated in boiling water. After full rehydration, the center of the millet grains became completely softened and the white core in its center position was justly lost. Cooking time was determined according to the method descried by Wang L. et al. [2013]. About $10 \mathrm{~g}$ of dried instant millet was put into $100 \mathrm{~mL}$ of boiling water for a while, during which the millet grains were taken out and observed, and the time lapsed was recorded till full rehydration.

\section{Microstructure}

Scanning electron microscope (EVO 15, Carl Zeiss AG, Oberkochen, Germany) was used to analyze the microstructure of the raw and dried millets. The specimen fragments were glued to the holder, sputter-coated with gold and examined for the inner structure and photographed at an accelerating voltage of $2 \mathrm{kV}$. The gold-coated samples were viewed under the microscope and a $\times 500$ magnification was used in all microscopic observations.

\section{Total yellow pigment content}

Total yellow pigment content in the raw and dried millet was determined using the method described by Shen et al. [2015]. Ground sample (2 g) was added to a $50 \mathrm{~mL}$ centrifuge tube, and combined with $20 \mathrm{~mL}$ of water-saturated $n$-butanol. After closing the stopper, the tube was mixed to fully wet the sample. The centrifuge tube was placed on a reciprocating shaker for $3 \mathrm{~h}$. Subsequently, the tube was allowed to stand for $10 \mathrm{~min}$ and then centrifuged at 4,000 $\times g$ (TDL-40B centrifuge, Anting, Shanghai, China) for $10 \mathrm{~min}$. The supernatants were collected and adjusted to $25 \mathrm{~mL}$ using the water-saturated $n$-butanol, then filtered through $0.45 \mathrm{~mm}$ filters. Water-saturated $n$-butanol blank was used as a control. The absorbance of sample extracts was measured at $450 \mathrm{~nm}$ with a $751 \mathrm{UV}$ -VIS spectrophotometer (Shanghai Analytical Instrument Factory, Shanghai, China). $\beta$-Carotene (Sigma Chemical Co., St. Louis, MO, USA) $(0-5 \mu \mathrm{g} / \mathrm{mL})$ was used as a standard for the calibration curve. The tests were performed in triplicate. Total yellow pigment content was expressed as mg $\beta$-carotene equivalent (CE) per kg of dry matter.

\section{Total phenolic content}

Total phenolic content in the raw and dried millet was determined with the Folin-Ciocalteau reagent [Singleton et al., 1999]. In brief, $3 \mathrm{~g}$ of the ground sample was extracted subsequently by a methanol:water solution acidified with $\mathrm{HCl}$ (50:50 v/v, pH 2, $25 \mathrm{~mL} / \mathrm{g}$ sample) and an acetone:water solution $(70: 30 \mathrm{v} / \mathrm{v}, 25 \mathrm{~mL} / \mathrm{g}$ sample) with continuous stirring at room temperature for $60 \mathrm{~min}$. The extracts were filtered through a Whatman No.1 filter paper, then the supernatants were combined and centrifuged at $3,000 \times g$ for $15 \mathrm{~min}$ (TDL$-40 \mathrm{~B}$ centrifuge). The obtained supernatant of $0.5 \mathrm{~mL}$ was mixed with $0.5 \mathrm{~mL}$ of the Folin-Ciocalteu reagent in a $25 \mathrm{~mL}$ glass-stopped tube. After $3 \mathrm{~min}, 10 \mathrm{~mL}$ of a sodium carbonate solution $(75 \mathrm{~g} / \mathrm{L})$ were added and mixed. Additional distilled water ( $14 \mathrm{~mL}$ was added up to make a final volume of $25 \mathrm{~mL}$ ) was added and then the sample was mixed thoroughly by inverting the tubes several times. After $1 \mathrm{~h}$, the absorbance at $750 \mathrm{~nm}$ was recorded with a $751 \mathrm{UV}-\mathrm{VIS}$ spectrophotometer.
Gallic acid (Sigma Chemical Co., 0-100 mg/L) was used as a standard for the calibration curve. The tests were performed in triplicate. Total phenolic content was expressed as mg gallic acid equivalent (GAE) per g of dry matter.

\section{Sensory evaluation}

Sensory evaluation of the dried and rehydrated samples was carried out separately to obtain preliminary information on consumer preference and eating quality of the dried millet. For the dried millet, ten untrained panelists (between 24 and 50 years old) were asked to rate their liking of the samples in terms of appearance, color, odor, tactility, mouthfeel, taste and overall acceptability on a 1 to 9 hedonic scale: 1 - dislike extremely, 5 - neither like nor dislike, 9 - like extremely [Lin et al., 1998]. The panelists were also asked to make comments and recommendations in regard to each sensory attribute. The rehydrated samples were made to the instant millet porridge and the instant millet beverage to evaluate their eating quality. These panelists gave a score on the overall acceptability of the product. A score of 5 or below was considered the limit of acceptability for all sensory attributes tested. To prepare the instant millet porridge, the dried little millet was poured into hot water and boiled for $6-8 \mathrm{~min}$ at the $1: 10(\mathrm{w} / \mathrm{v})$ ratio of millet to water. The instant millet beverage was prepared by crushing the dried sample followed by brewing with hot water, which consisted of $15 \mathrm{~g}$ of millet flour, $5 \mathrm{~g}$ of sucrose and $200 \mathrm{~mL}$ of hot water. The sensory evaluation was performed in triplicate.

\section{Statistical analysis}

All data obtained in this study were analyzed statistically. The results were expressed as means \pm standard deviation (SD). Differences among mean values were estimated by analysis of variance (ANOVA) with the application of Duncan's multiple range tests using SPSS 17.0.1 software (SPSS Inc., Chicago, IL, USA). Mean values were considered significantly different when $p<0.05$.

\section{RESULTS AND DISCUSSIONS}

\section{Characteristics of millet drying}

The initial moisture content of the cooked millets prior to MVD, MHAD and HAD was found to be $1.23 \mathrm{~kg}$ water $/ \mathrm{kg}$ dry matter while the one of the raw millets before TR was found to be $0.14 \mathrm{~kg}$ water $/ \mathrm{kg}$ dry matter. Figure la presents the variation of moisture content with drying time under the four different drying conditions. The moisture content sharply decreased at the initial drying stage and subsequently slowly reduced as MVD, MHAD and HAD proceeded. On the other hand, the curve of moisture content vs. time had a gentle incline for TR. These differences may have been due to great differences in initial moisture content of the samples. The total drying time reached the desired moisture content of $0.07 \mathrm{~kg}$ water $/ \mathrm{kg}$ dry matter was about 160, 100, 260, and $45 \mathrm{~min}$ for MVD, MHAD, HAD and TR, respectively. TR drying time of the instant little millets was the shortest while the HAD one was the longest. Compared with HAD, both MHAD and MVD could reduce the drying time of the instant millets by $38.5-61.5 \%$ due to microwave fast heating capacity. Comparable findings were reported while drying instant 

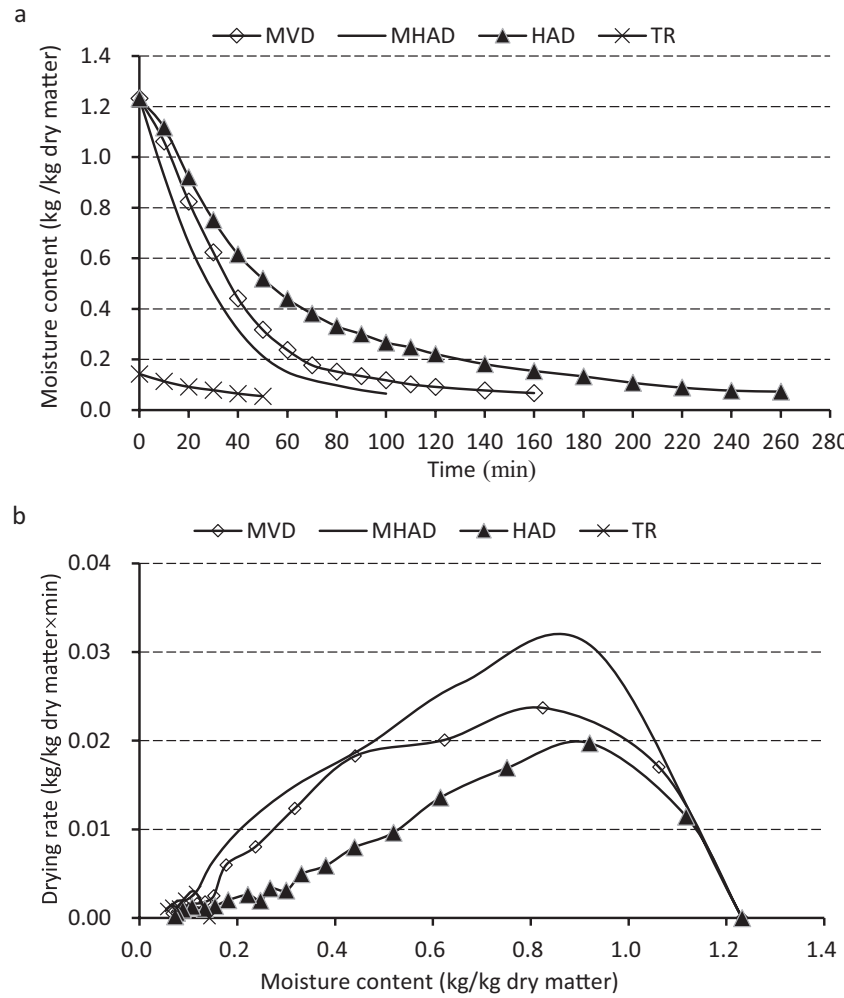

FIGURE 1. Drying curves (a) and drying rate curves (b) of the instant foxtail millet with different drying methods. MVD: microwave-vacuum drying, MHAD: microwave-hot air drying, HAD: hot air drying, TR: traditional roasting.

rice [Jiao et al., 2014; Palamanit et al., 2020]. The mentioned authors found that the incorporation of microwave power with hot air drying helped to reduce the drying time by $25-50 \%$ in comparison with the conventional hot air drying.

Drying rate, a function of drying time and moisture content, was a fundamental parameter that was computed from the drying data by estimating geometric derivation occurring in each consecutive time interval, and was expressed as $\mathrm{kg}$ water/(kg dry matter $\times$ min). Figure $1 \mathrm{~b}$ depicts the variation of drying rate with moisture content in the millet under the four drying conditions. Drying method had a strong influence on drying rate curve. HAD and MVD underwent a warm-up, raising speed period at the beginning, followed by a falling rate period for a long time while MHAD only underwent a falling rate period due to the difference in moisture movement capacity and heat transfer. The moisture movement behavior including diffusion and vaporization during drying of food depended on the drying conditions and the characteristic of the material to be dried [Zogzas et al., 1996]. A falling rate drying signified that the drying process was controlled by the inner water diffusion [Schoessler et al., 2012; Wang et al., 2019b].

The graph of experimental values of $\ln M R$ of the millet against drying time was plotted for each drying method, and the $D_{\text {eff }}$ of the millet was calculated according to Eq. 7 and presented in Table 1. The coefficients of determination $\left(R^{2}\right)$ of linear regression for $\ln M R$ against time presented values greater than 0.95 , which indicated a good linear relationship between $\ln M R$ and time. The $D_{\text {eff }}$ was in the range from $6.57 \times 10^{-9} \mathrm{~m}^{2} / \mathrm{s}$ to $9.80 \times 10^{-9} \mathrm{~m}^{2} / \mathrm{s}$, with the highest value
TABLE 1. Effective moisture diffusion coefficient $\left(D_{\text {eff }}\right)$ of the instant foxtail millet obtained with different drying methods.

\begin{tabular}{lcc}
\hline Drying method & $R^{2}$ & $D_{\text {eff }}\left(\times 10^{-9} \mathrm{~m}^{2} / \mathrm{s}\right)$ \\
\hline MVD & 0.9563 & $6.57 \pm 0.85^{\mathrm{b}}$ \\
MHAD & 0.9839 & $9.80 \pm 0.67^{\mathrm{a}}$ \\
HAD & 0.9313 & $4.14 \pm 0.12^{\mathrm{c}}$ \\
TR & 0.9888 & $6.20 \pm 0.34^{\mathrm{b}}$ \\
\hline
\end{tabular}

Data are presented as mean \pm standard deviation $(n=3)$ and means within a column with different letters are significantly different at $p<0.05$. MVD: microwave-vacuum drying, MHAD: microwave-hot air drying, HAD: hot air drying, TR: traditional roasting, $R^{2}$ : coefficient of determination of linear regression.

determined for MHAD followed by MVD. The lowest $D_{\text {eff }}$ was found for HAD. The values of $D_{\text {eff }}$ obtained from this study were in the range typical for food materials drying (from $10^{-12}$ to $10^{-8} \mathrm{~m}^{2} / \mathrm{s}$ ) [Zogzas et al., 1996]. The effective moisture diffusivity was associated with the drying conditions and the nature of the material to be dried (material thickness, initial moisture content, moisture state as well as the cell disruption induced by different pre-treatments) [Chong et al., 2008; Wang et al., 2019b; Zogzas et al., 1996].

\section{Physical properties of raw and dried instant millet}

\section{Color parameters}

Color of food is an important attribute which influences consumer acceptability. The raw foxtail millet presented a pale yellow due to the presence of crude starch and yellow pigment. The color parameters including $L^{*}, a^{*}, b^{*}, \mathrm{C}^{*}, \Delta E$ and $h^{\circ}$ of both the raw and the dried instant millet were determined and the results were listed in Table 2. Drying operation resulted in a significant $(p<0.05)$ decrease in the $L^{*}$ value and a significant $(p<0.05)$ increase in $a^{*}, b^{*}$, and $C^{*}$ values of the dried millets in comparison with the raw sample. Lower $L^{*}$ indicated more dark color while higher $a^{*}$ and $b^{*}$ value signifies lighter red color and lower blue color, respectively. This indicates that the final dried millet became darker and appeared light brown. Similar results were found in the fluidized bed drying of finger millets and roasted pigmented wheat [Dhua et al., 2021; Shingare \& Thorat, 2013].

The $a^{*}$ and $b^{*}$ and $C^{*}$ value in TR products were significantly $(p<0.05)$ lower than that of the three dried products after cooking (Table 2). In turn, there were no significant $(p \geq 0.05)$ differences between $a^{*}$ and $b^{*}$ and $C^{*}$ values of the MHAD and MVD and HAD products. The MHAD and MVD products had also a comparable value of the $L^{*}$, but it was significantly $(p<0.05)$ higher than that found for the HAD product. The TR product had a minimum value of $\Delta E$ while a maximum value of $\Delta E$ was observed in HAD product, which indicates that the color of TR product is closest to the original color of the raw millet.

The hue angle $\left(h^{\circ}\right)$ for both the raw and all the dried samples was in the range of $73.5-82.8^{\circ}$ (Table 2), which was located in a color nuance between red-purple to yellow and tended to be yellow. The raw and TR products were more 
TABLE 2. Color parameters of the raw and instant foxtail millet obtained with different drying methods.

\begin{tabular}{l|c|c|c|c|c|c}
\hline Treatment & $L^{*}$ & $a^{*}$ & $b^{*}$ & $C^{*}$ & $h^{o}$ & $\Delta E$ \\
\hline Raw & $71.10 \pm 2.21^{\mathrm{a}}$ & $3.29 \pm 0.26^{\mathrm{c}}$ & $25.90 \pm 1.09^{\mathrm{c}}$ & $26.11 \pm 1.22^{\mathrm{c}}$ & $82.80 \pm 2.34^{\mathrm{a}}$ & \\
MVD & $56.03 \pm 1.32^{\mathrm{c}}$ & $9.04 \pm 0.89^{\mathrm{a}}$ & $32.17 \pm 1.43^{\mathrm{a}}$ & $33.42 \pm 1.65^{\mathrm{a}}$ & $74.34 \pm 2.33^{\mathrm{c}}$ & $16.32 \pm 1.12^{\mathrm{b}}$ \\
MHAD & $55.75 \pm 1.23^{\mathrm{c}}$ & $9.56 \pm 0.67^{\mathrm{a}}$ & $32.19 \pm 1.07^{\mathrm{a}}$ & $33.58 \pm 1.98^{\mathrm{a}}$ & $73.50 \pm 1.34^{\mathrm{c}}$ & $16.60 \pm 1.09^{\mathrm{b}}$ \\
HAD & $50.61 \pm 0.98^{\mathrm{d}}$ & $9.21 \pm 0.98^{\mathrm{a}}$ & $33.22 \pm 1.55^{\mathrm{a}}$ & $34.47 \pm 2.34^{\mathrm{a}}$ & $74.54 \pm 2.34^{\mathrm{c}}$ & $21.76 \pm 1.34^{\mathrm{a}}$ \\
TR & $65.14 \pm 2.34^{\mathrm{b}}$ & $6.46 \pm 0.46^{\mathrm{b}}$ & $28.58 \pm 1.67^{\mathrm{b}}$ & $29.30 \pm 1.78^{\mathrm{b}}$ & $77.30 \pm 3.24^{\mathrm{b}}$ & $7.03 \pm 0.56^{\mathrm{c}}$ \\
\hline
\end{tabular}

Data are presented as mean \pm standard deviation $(n=3)$ and means within a column with different letters are significantly different at $p<0.05$. MVD: microwave-vacuum drying, MHAD: microwave-hot air drying, HAD: hot air drying, TR: traditional roasting.

yellow than the dried products after cooking. The differences in color values of the products might be related to structural changes of starch granule, browning reaction including Maillard reaction and caramelization favored by heat as well as change in yellow pigment concentration during processing and these multiple factors are responsible for color changes [Dhua et al., 2021; Shingare \& Thorat, 2013].

\section{Rehydration characteristics and cooking time}

Most dehydrated products need to be rehydrated prior to use; rapid and complete rehydration when immersed in water is desirable. Additionally, rehydration is a measure of damage to the material caused during drying [Wang et al., 2019a]. Figure 2a presents the variation of the rehydration ratio $v s$. time for the four dried millets during rehydration at room temperature for $300 \mathrm{~min}$. In all cases, the rehydration ratio tended to reach a relative stabilization state at a decreasing rate. The rehydration curves for MVD, MHAD and HAD products overlapped each other and presented a similar rehydrated behavior. It was indicated that microwave heating caused no damage to the structure of the cooked millet during drying and the dried millet products maintained the typical structure in the non-polypass gelatinized starch products like instant rice [Luangmalawat et al., 2008; Palamanit et al., 2020], vermicelli and rice flour noodles [Xing et al., 2015]. TR product had a faster rate but a lower rehydration ratio than the other three products due to millet cracking caused by high temperature. The rehydration ratios of MVD, MHAD, HAD and TR instant little millet were 2.67, 2.61, 2.65 and 1.82 at $300 \mathrm{~min}$, respectively. There were also no significant $(p \geq 0.05)$ differences observed in the dried products after cooking.

Figure $2 \mathrm{~b}$ presents the cooking time of the instant foxtail millet with different drying methods. Cooking time for the MVD, MHAD, HAD and TR millet was $352 \mathrm{~s}, 348 \mathrm{~s}$, $349 \mathrm{~s}$ and $559 \mathrm{~s}$, respectively. It was indicated that the millet porridge could be prepared in a short time from these instant millet products. MVD, MHAD and HAD products had a comparable $(p \geq 0.05)$ cooking time and their cooking time was significantly $(p<0.05)$ shorter than that of the TR millet.

\section{Microstructure of the instant millet}

In order to understand the structure changes in the instant millets caused by the drying methods, the microstructures of the raw and dried millet were observed using scanning electron microscopy and were shown in Figure 3.
It can be seen that both the raw millet and TR product had a similar and rough inner structure, where the crude starch granule with a crystal structure was embed in the fragment of the millet grain. In the MVD, HAD and MHAD products, the fragment of the millet grain appeared a fine, smooth and dense surface due to recrystallization of gelatinized starch. There were no obvious differences observed among them. A porous and obviously expanded structure easily developed in microwave-related drying of many food materials such as restructured fish and starch gel product [Wang Y. et al., 2012; 2013] and fruit slices [Lin et al., 1998; Zhang et al., 2006] was not found in this study. Probably a viscoelastic gel structure that can trap water vapor and higher microwave power density applied can expand more readily under microwave volumetric heating. Similar microstructure observed in the dried millets after cooking led to insignificant differences in the rehydration curve of the rehydrated millet as mentioned in the previous section. This result
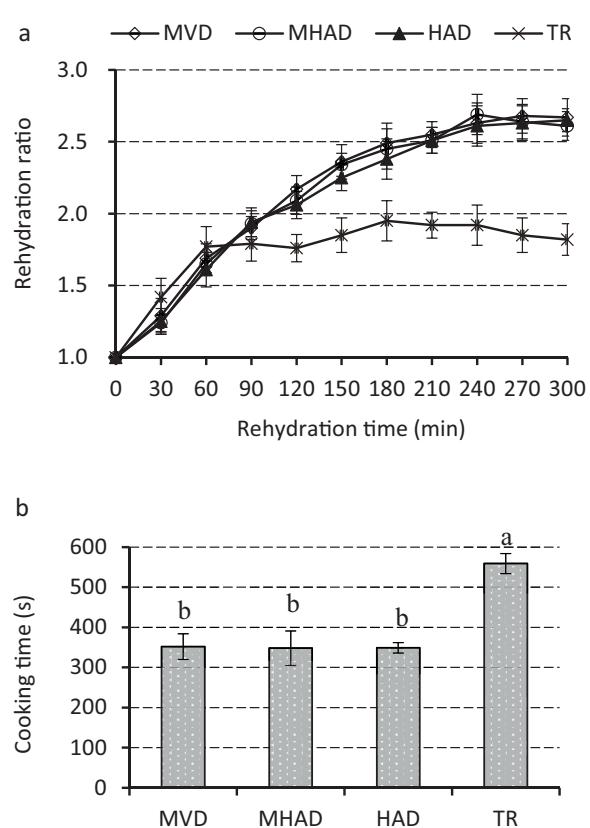

FIGURE 2. Rehydration curves (a) and cooking time (b) of the instant foxtail millet obtained with different drying methods. Data are presented as bars with mean \pm standard deviation $(n=3)$ and means with different letters are significantly different at $p<0.05$. MVD: microwave-vacuum drying, MHAD: microwave-hot air drying, HAD: hot air drying, TR: traditional roasting. 
was in agreement with the findings of Luangmalawat et al. [2008] and Palamanit et al. [2020]. They found that drying temperature and application of microwave power in hot air drying did not affect the rehydration ratio and microstructure of the instant rice.

\section{Total phenolic and yellow pigment contents of raw and dried instant millet}

Phenolics and yellow pigments are the most important phytochemicals present in foxtail millet grains, which play an important role in imparting antioxidant property to the grains [Sharma \& Niranjan, 2018]. The main component of millet yellow pigment is natural carotenoids which are believed to impart yellow color to the foxtail millet grains except for healthy effect [Shen et al., 2015]. Figure 4 shows total phenolic and yellow pigment contents in the raw millet and the instant millet dried using different methods. Total phenolic and yellow pigment contents in the raw millet were $152.45 \mathrm{mg}$ GAE/100 g dry matter and $15.51 \mathrm{mg}$ CE/kg dry matter, respectively. In the dried millets, total phenolic content ranged from $142.56 \mathrm{mg}$ GAE/100 g dry matter to $68.77 \mathrm{mg}$ GAE/100 g dry matter while yellow pigment content was in the range of $9.56 \mathrm{mg} \mathrm{CE} / \mathrm{kg}$ dry matter to $5.86 \mathrm{mg} \mathrm{CE} / \mathrm{kg}$ dry matter. Drying caused a loss of $6.5-54.9 \%$ in the total phenolic content and a loss of 38.4-62.2\% in total yellow pigment content and there were significant $(p<0.05)$ differences among dried millets. MVD dried millet displayed the highest total phenolic and yellow pigment contents due to the oxygen-free condition and shorter drying time, followed by the MHAD and HAD; both the total phenolic and yellow pigment contents of the TR sample were the lowest because of roasting at high temperature. This result indicated that MVD and MHAD was more beneficial to the retention of phenolics and yellow pigments in the millet than the other drying method.
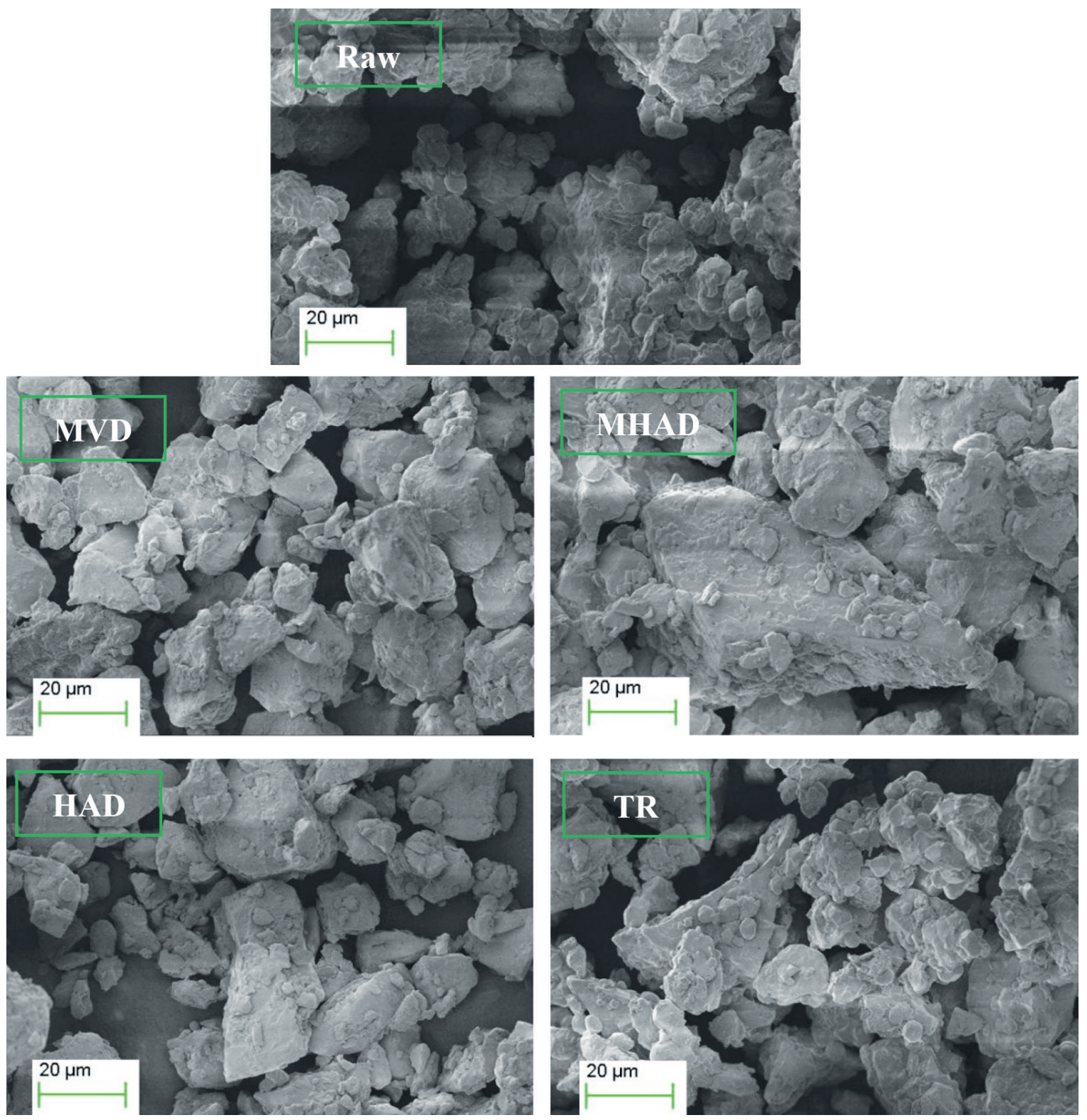

FIGURE 3. Scanning electron micrographs of the raw and instant foxtail millet obtained with different drying methods. MVD: microwave-vacuum drying, MHAD: microwave-hot air drying, HAD: hot air drying, TR: traditional roasting. 

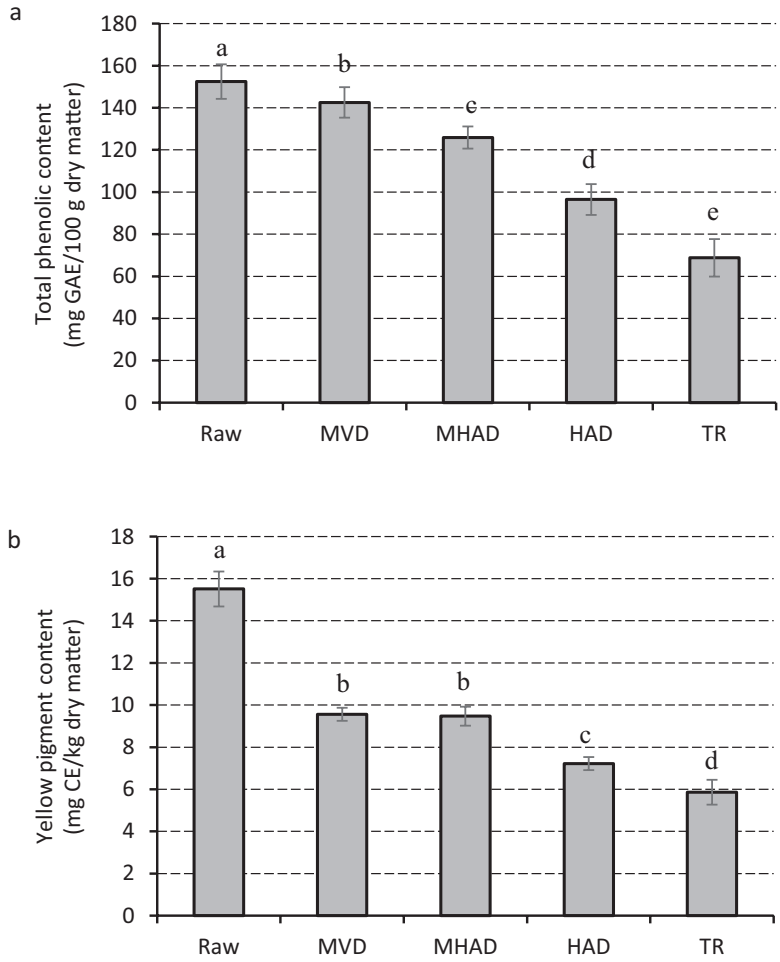

FIGURE 4. Total phenolic content (a) and total yellow pigment content (b) of the raw and instant foxtail millet obtained with different drying methods. Data are presented as bars with mean \pm standard deviation $(n=3)$ and means with different letters are significantly different at $p<0.05$. MVD: microwave-vacuum drying, MHAD: microwave-hot air drying, HAD: hot air drying, TR: traditional roasting, GAE: gallic acid equivalent, CE: $\beta$-carotene equivalent.

Phenolics and yellow pigments in food systems are sensitive to heat, and deterioration reactions easily occur during the thermal process like cooking and drying. The loss of total phenolic content due to drying was found for microwave-dried green peas [Chahbani et al., 2018], steam- and microwave-treated small millets [Hithamani \& Srinivasan, 2014] and microwave-roasted pigmented wheat [Dhua et al., 2021]. Carotenoid degradation reactions, including isomerization and oxidation, are known to occur easily during a thermal process [Shen et al., 2015]. These reactions caused also the instability and loss of the carotenoids of foxtail millet during cooking and drying. Shen et al. [2015] found that the atmospheric-pressure cooking and high-pressure cooking resulted in an around 10-20\% and $60 \%$, respectively, loss of total yellow pigment contents in the foxtail millet.

\section{Sensory score of the dried instant millet and rehydrated products}

Table 3 lists the results of sensory evaluation for both the dried and rehydrated millet products. In dry form, the MHAD, HAD and MVD samples showed no significant $(\mathrm{p} \geq 0.05)$ differences in sensory evaluation and were all characterized by a transparent, hard and granular appearance, a more yellow color and a full-bodied millet fragrance while the TR sample had a crispy mouthfeel, pale color, globular appearance and roasted aroma. The former three products presented a light sweet taste and were superior to the TR one. The popcorn-like and smoky odors were noted for roasted foxtail millet, and the development of pyrazines contributed to the odor. Each sensory attribute for all the dried samples except mouthfeels was scored above 5 and was ranked as liked very much or slightly liked by the panelists. As for overall acceptability, they were all accepted by the panelists as a commodity although TR product had a lower score than the others.

With regard to eating quality after rehydration, the MHAD, HAD and MVD samples were scored above 7 as porridge and were all accepted by the panelists while TR one was scored below 4 and was not accepted by the panelists. When eating as beverage, all the instant millets were scored above 7 and were all accepted by the panelists. Moreover, the panelists preferred the TR sample to the other three samples due to the presence of roasted aroma.

\section{CONCLUSION}

Based on results of the present investigation, we concluded that the drying methods have profound effect on the drying kinetics and quality of the dried instant foxtail millet. As compared with the conventional HAD and TR, microwave-assisted drying including MVD and MHAD had shorter drying time and higher drying rate, which could reduce the drying time of the instant little millets by $38.5-61.5 \%$. Moreover, MVD and MHAD samples possessed higher total phenolic and yellow pigment contents as well as excellent physical and sensory indexes. MVD and MHAD are suitable for drying the instant millet, and the instant millet obtained could be used as the food to make quick-cooking porridge or beverage.

TABLE 3. Results of sensory evaluation of the instant foxtail millet obtained with different drying methods and products from instant foxtail millets.

\begin{tabular}{|c|c|c|c|c|c|c|c|c|c|}
\hline \multirow{2}{*}{ Drying methods } & \multirow{2}{*}{ Color } & \multirow{2}{*}{ Odor } & \multirow{2}{*}{ Appearance } & \multirow{2}{*}{ Tactility } & \multirow{2}{*}{ Mouthfeel } & \multirow{2}{*}{ Taste } & \multirow{2}{*}{$\begin{array}{c}\text { Overall } \\
\text { acceptability }\end{array}$} & \multicolumn{2}{|c|}{ Eating quality } \\
\hline & & & & & & & & Porridge & Beverage \\
\hline MVD & $8.2 \pm 0.4^{\mathrm{a}}$ & $8.5 \pm 0.1^{\mathrm{a}}$ & $8.3 \pm 0.2^{\mathrm{a}}$ & $7.3 \pm 0.4^{b}$ & $2.0 \pm 0.2^{\mathrm{b}}$ & $7.3 \pm 0.2^{\mathrm{a}}$ & $8.3 \pm 0.2^{\mathrm{a}}$ & $7.4 \pm 0.1^{\mathrm{a}}$ & $7.2 \pm 0.2^{\mathrm{b}}$ \\
\hline MHAD & $8.1 \pm 0.2^{\mathrm{a}}$ & $8.3 \pm 0.4^{\mathrm{a}}$ & $8.2 \pm 0.1^{\mathrm{a}}$ & $7.1 \pm 0.3^{\mathrm{b}}$ & $1.9 \pm 0.3^{b}$ & $7.2 \pm 0.1^{\mathrm{a}}$ & $8.2 \pm 0.1^{\mathrm{a}}$ & $7.8 \pm 0.3^{\mathrm{a}}$ & $7.5 \pm 0.3^{b}$ \\
\hline HAD & $8.3 \pm 0.3^{\mathrm{a}}$ & $8.1 \pm 0.2^{\mathrm{a}}$ & $8.3 \pm 0.3^{\mathrm{a}}$ & $7.2 \pm 0.6^{\mathrm{b}}$ & $2.1 \pm 0.2^{b}$ & $7.3 \pm 0.3^{\mathrm{a}}$ & $8.3 \pm 0.3^{\mathrm{a}}$ & $7.1 \pm 0.2^{\mathrm{a}}$ & $7.1 \pm 0.2^{\mathrm{b}}$ \\
\hline TR & $7.5 \pm 0.2^{b}$ & $8.8 \pm 0.3^{\mathrm{a}}$ & $8.0 \pm 0.5^{\mathrm{a}}$ & $8.6 \pm 0.2^{\mathrm{a}}$ & $5.5 \pm 0.1^{\mathrm{a}}$ & $5.5 \pm 0.5^{\mathrm{b}}$ & $7.0 \pm 0.5^{\mathrm{b}}$ & $3.9 \pm 0.2^{b}$ & $8.5 \pm 0.2^{\mathrm{a}}$ \\
\hline
\end{tabular}

Data are presented as mean \pm standard deviation $(n=3)$ and means within a column with different letters are significantly different at $p<0.05$. MVD: microwave-vacuum drying, MHAD: microwave-hot air drying, HAD: hot air drying, TR: traditional roasting. 


\section{RESEARCH FUNDING}

The authors gratefully acknowledged the financial supports provided by the National Natural Science Foundation of China (No.31460398 and No.32060544) and the Scientific Research Starting Foundation for Doctor (No.2014XYBY1) and Youth Science and Technology Innovation Project (No. XYZK1707) of Longdong University.

\section{DECLARATION OF CONFLICTING INTERESTS}

The authors declare no potential conflicts of interest with respect to the research, authorship, and/or publication of this article.

\section{ORCID IDs}

Y. Wang https://orcid.org/0000-0002-7186-2367

H. Zhao https://orcid.org/0000-0001-6523-3233

\section{REFERENCES}

1. AOAC. 1997. Official Methods of Analysis of the Association of Official Analytical Chemists. 16th ed. Washington, DC.

2. Bi, S., Wang, A., Wang, Y., Xu, X., Luo, D., Shen, Q., Wu, J. (2019). Effect of cooking on aroma profiles of Chinese foxtail millet (Setaria italica) and correlation with sensory quality. Food Chemistry, 289(15), 680-692.

https://doi.org/10.1016/j.foodchem.2019.03.108

3. Chahbani, A., Fakhfakh, N., Balti, M.A., Mabrouk, M., El-Hatmi, H., Zourai, N., Kechaou, N. (2018). Microwave drying effects on drying kinetics, bioactive compounds and antioxidant activity of green peas (Pisum sativum L.). Food Bioscience, 25, 32-38. https://doi.org/10.1016/j.fbio.2018.07.004

4. Chong, C.H., Law, C.L., Cloke, M., Hii, C.L., Abdullah, L.C., Daud, W.R. W. (2008). Drying kinetics and product quality of dried Chempedak. Journal of Food Engineering, 88(4), 522-527.

https://doi.org/10.1016/j.jfoodeng.2008.03.013

5. Dhua, S., Kheto, A., Sharanagat, V.S., Singh, L., Kumar, K., Nema, P.K. (2021). Quality characteristics of sand, pan and microwave roasted pigmented wheat (Triticum aestivum). Food Chemistry, 365, art. no. 130372.

https://doi.org/10.1016/j.foodchem.2021.130372

6. FAO (2005). Sorghum and millets in human nutrition. FAO Food and Nutrition Series, No.68. Rome, p. 277.

7. Hithamani, G., Srinivasan, K. (2014). Effect of domestic processing on the polyphenol content and bioaccessibility in finger millet (Eleusine coracana) and pearl millet (Pennisetum glaucum). Food Chemistry, 164, 55-62.

https://doi.org/10.1016/j.foodchem.2014.04.107

8. Hsu, R.J.C., Chen, H.J., Lu, S., Chiang, W.C. (2015). Effects of cooking, retrogradation and drying on starch digestibility in instant rice making. Journal of Cereal Science, 65, 154-161. https://doi.org/10.1016/j.jcs.2015.05.015

9. Jiao, A., Xu, X., Jin, Z. (2014). Modelling of dehydration-rehydration of instant rice in combined microwave-hot air drying. Food and Bioproducts Processing, 92(3), 259-265.

https://doi.org/10.1016/j.fbp.2013.08.002
10. Kaya, A., Aydin, O., Demirtas, C., Akgün, M. (2007). An experimental study on the drying kinetics of quince. Desalination, 212(1-3), 328-343.

https://doi.org/10.1016/j.desal.2006.10.017

11. Le, T.Q., Jittanit, W. (2012). Drying characteristics of cooked jasmine brown rice and true densities of dried products. Kasetsart Journal (Natural Science), 46, 256-271.

12. Le, T.Q., Jittanit, W. (2015). Optimization of operating process parameters for instant brown rice production with microwave-followed by convective hot air drying. Journal of Stored Products Research, 61, 1-8.

https://doi.org/10.1016/j.jspr.2015.01.004

13. Lenaerts, S., Borght, M.V.D., Callens, A., Van Campenhout, L. (2018). Suitability of microwave drying for mealworms (Tenebrio molitor) as alternative to freeze drying: Impact on nutritional quality and color. Food Chemistry, 254, 129-136. https://doi.org/10.1016/j.foodchem.2018.02.006

14. Li, S., Zhao, W., Liu, S., Li, P., Zhang, A., Zhang, J., Wang, Y., Liu, Y., Liu, J. (2021). Characterization of nutritional properties and aroma compounds in different colored kernel varieties of foxtail millet (Setaria italica). Journal of Cereal Science, 100, art. no. 103248 .

https://doi.org/10.1016/j.jcs.2021.103248.

15. Lin, T.M., Durance, T.D., Scaman, C.H. (1998). Characterization of vacuum microwave, air and freeze dried carrot slices. Food Research International, 31 (2), 111-117. https://doi.org/10.1016/S0963-9969(98)00070-2

16. Luangmalawat, P., Prachayawatakorn, S., Nathakaranakule, A., Soponronnarit, S. (2008). Effect of temperature on drying characteristic and quality of cooked rice. LWT - Food Science and Technology, 41 (4), 716-723.

https://doi.org/10.1016/j.Iwt.2007.04.010

17. Palamanit, A., Sugira, A.M., Soponronnarit, S., Prachayawarakorn, S., Tungtrakul, P., Kalkan, F., Raghavan, V. (2020). Study on quality attributes and drying kinetics of instant parboiled rice fortified with turmeric using hot air and microwave-assisted hot air drying. Drying Technology, 38(4), 420-433.

https://doi.org/10.1080/07373937.2019.1579735

18. Pradeep, P.M., Sreerama, Y.N. (2015).Impact of processing on the phenolic profiles of small millets: Evaluation of their antioxidant and enzyme inhibitory properties associated with hyperglycemia. Food Chemistry, 169, 455-463.

https://doi.org/10.1016/j.foodchem.2014.08.010

19. Rewthong, O., Soponronnarit, S., Taechapairoj, C., Tungtrakul, P., Prachayawarakorn, S. (2011). Effects of cooking, drying, and pretreatment methods on texture and starch digestibility of instant rice. Journal of Food Engineering, 103(3), 258-264. https://doi.org/10.1016/j.jfoodeng.2010.10.022

20. Ritudomphol, O., Luangsakul, N. (2019). Optimization of processing condition of instant rice to lower the glycemic index. Journal of Food Science, 84(1), 101-110. https://doi.org/10.1111/1750-3841.14406

21. Saleh, A.S.M., Zhang, Q., Chen, J., Shen, Q. (2013). Millet grains: nutritional quality, processing, and potential health benefits. Comprehensive Reviews in Food Science \& Food Safety, 12 (3), 281-295.

https://doi.org/10.1111/1541-4337.12012

22. Schoessler, K., Jaeger, H., Knorr, D. (2012). Effect of continuous and intermittent ultrasound on drying time and effective diffusiv- 
ity during convective drying of apple and red bell pepper. Journal of Food Engineering, 108(1), 103-110.

https://doi.org/10.1016/j.jfoodeng.2011.07.018

23. Sharma, N., Niranjan, K. (2018). Foxtail millet: properties, processing, health benefits, and uses. Food Reviews International, 34(4), 329-363.

https://doi.org/10.1080/87559129.2017.1290103

24. Shen, R., Yang, S.P., Zhao, G.H., Shen, Q., Diao, X.M. (2015). Identification of carotenoids in foxtail millet (Setaria italica) and the effects of cooking methods on carotenoid content. Journal of Cereal Science, 61, 86-93.

https://doi.org/10.1016/j.jcs.2014.10.009

25. Shingare, S.P., Thorat, B.N. (2013). Effect of drying temperature and pretreatment on protein content and color changes during fluidized bed drying of finger millets (Ragi, Eleusine coracana) sprouts. Drying Technology, 31 (5), 507-518.

https://doi.org/10.1080/07373937.2012.744033

26. Singleton, V.L., Orthofer, R., Ramuela-Raventos, R.M. (1999). Analysis of total phenols and other oxidation substrates and antioxidants by means of Folin-Ciocalteu reagent. Oxidants and Antioxidants, 299(1), 152-178.

https://doi.org/10.1016/S0076-6879(99)99017-1

27. Sripinyowanich, J., Noomhorm, A. (2013). Effects of freezing pretreatment, microwave assisted vibro-fluidized bed drying and drying temperature on instant rice production and quality. Journal of Food Processing and Preservation, 37(4), 314-324. https://doi.org/10.1111/j.1745-4549.2011.00651.x

28. Wang, Q., Li, S., Han, X., Ni, Y., Zhao, D., Hao, J. (2019a). Quality evaluation and drying kinetics of shitake mushrooms dried by hot air, infrared and intermittent microwave-assisted drying methods. LWT - Food Science and Technology, 107, 236-242.

https://doi.org/10.1016/j.Iwt.2019.03.020

29. Wang, Y., Zhao, H., Deng, H., Song, X., Zhang, W., Wu, S., Wang, J. (2019b). Influence of pretreatments on microwave vacuum drying kinetics, physicochemical properties and sensory quality of apple slices. Polish Journal of Food and Nutrition Sciences, 69(3), 297-306.

https://doi.org/10.31883/pjfns/110734

30. Wang, R.C., Chen, C., Guo, S.T. (2017). Effects of drying methods on starch crystallinity of gelatinized foxtail millet ( $\alpha$-millet) and its eating quality. Journal of Food Engineering, 207, 81-89. https://doi.org/10.1016/j.jfoodeng.2017.03.018

31. Wang, L., Zhang, G., Bao, G., Zhang, L. (2013). Study on rehydration of instant millet gruel by microwave and hot air combined drying. Cereal and Feed Industry, 12 (6), 25-28.

32. Wang, Y., Zhang, M., Mujumdar, A.S. (2013). Effect of cassava starch gel, fish gel and mixed gels and thermal treatment on structure development and various quality parameters in microwave vacuum-dried gel slices. Food Hydrocolloids, 33(1), 26-37. https://doi.org/10.1016/j.foodhyd.2013.02.005

33. Wang, Y., Zhang, M., Mujumdar, A.S., Mothibe, K.J. (2012). Quality changes of dehydrated restructured fish product from silver carp as affected by drying methods. Food and Bioprocess Technology, 6(7), 1664-1680. https://doi.org/10.1007/s11947-012-0812-y

34. Xing, L.J., Mu, T.H., Zhang, M., Yu, S.X., Chen, J.W., Yang, H.Y. (2015). Effects of different low-temperature and drying treatment on the properties of purple sweet potato starch noodle. Food Science and Technology, 40(3), 15-121.

35. Zogzas, N.P., Maroulis, Z.B., Marinos-Kouris, D. (1996). Moisture diffusivity data compilation in foodstuffs. Drying Technology, 14(10), 2225-2253.

https://doi.org/10.1080/07373939608917205

36. Zhang, M., Tang, J.M., Mujumdar, A.S., Wang, S. (2006). Trends in microwave-related drying of fruits and vegetables. Trends in Food Science \& Technology, 17(10), 524-534. https://doi.org/10.1016/j.tifs.2006.04.011

37. Zhang, L., Li, J., Han, F., Ding, Z., Fan, L. (2017). Effects of different processing methods on the antioxidant activity of 6 cultivars of foxtail millet. Journal of Food Quality, 2017(SI), art. no. 8372854 .

https://doi.org/10.1155/2017/8372854 